\title{
Identification of the major chemical constituents and their metabolites in rat plasma and various organs after oral administration of effective EXD fraction by liquid chromatography-mass spectrometry
}

\author{
Yong Mei Hua, Yi Tao Wang ${ }^{b}$, Cho-Wing Sze ${ }^{a}$, Qing Liu ${ }^{a}$, Li Dan Zhong ${ }^{a}$ and \\ Yao Tong ${ }^{\text {a* }}$
}

\begin{abstract}
A simple and specific LC-DAD-ESI-MS/MS method has been developed and applied for the primary investigation of the chemical constituents absorbed or metabolized in vivo, after the rat oral administration of Erxian Decoction (EXD), a

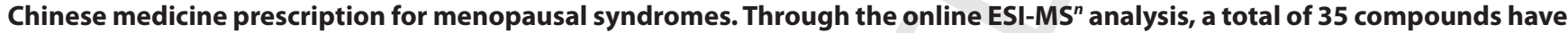
been identified or tentatively characterized from the seven tested samples, and 13 of them were unambiguously identified through a direct comparison of the retention time, UV spectra and MS $^{n}$ fragmentation patterns with the authentic ones. The results showed that 21 compounds were detected from rat plasma, 20 compounds were detected from rat kidneys and adrenal glands, 19 compounds were detected from rat ovaries, 12 compounds were found in rat intestines, nine compounds were identified from rat livers and nine compounds were detected from rat brains at certain time points after oral administration of the effective EXD fraction. Copyright $\odot 2009$ John Wiley \& Sons, Ltd.
\end{abstract}

Keywords: LC-DAD-ESI-MS; Erxian Decoction (EXD); traditional Chinese medicine prescriptions (TCMP); menopausal syndromes; pharmacokinetic study; metabolites

\section{Introduction}

Traditional Chinese medicine prescriptions (TCMP) have been practiced in China for more than 2000 years with few side-effects. However, different from Western medicines, TCM prescriptions are usually made up of several Chinese herbs, which usually contain hundreds of chemical constituents, and this make it hard to explain which constituents are responsible for its therapeutic properties. The multiplicity of the chemical materials and the dimness of their action mechanisms have seriously restricted the development of TCMP in the international market. A simple and effective analytical method to reveal the possible active constituents in vivo is in great demand and proved to be significant. In recent years, the combined LC-DAD-MS ${ }^{n}$ technique has become a much popular approach for the rapid identification of the highly polar and non-volatile chemical constituents contained in biological matrices at trace levels with the on-line DAD and MS detection method (Ma et al., 2008; Ge et al., 2007; Wang et al., 2005).

Erxian Decoction, composed of Curculigo orchioides Gaertn. (Rhizome), Epimedium brevicornum Maxim. (Aerial herb), Morinda Officinalis (Root), Anemarrhenae asphodeloides Bge. (Rhizome), Phellodendron chinense Schneid. or Phellodendron amurense Rupr. (Bark), and Angelica sinensis (Oliv.) Diels (Root), has been practiced for the treatment of menopausal syndromes since the 1950s in China. Modern pharmacological research has revealed that EXD has a comprehensive effect on such multiple targets as hypothala- mus-pituitary-target gland axis, immune function and free radical metabolism (Liu et al., 2005; Nian et al., 2006). Our recent study also suggested that EXD treatment would result in increased circulatory estrogen level via the activation of aromatase-related pathway (Sze et al., 2009). The constituents of EXD are numerous and diverse, including alkaloids, phenols, saponins, polysaccharides and oligosaccharides, and many of them have been reported to possess a wide range of bioactivities (Chen et al., 2007, 2008; Kite et al., 2007; Lu et al., 2006; Gong et al., 2003). However, like most of the TCM prescriptions, it remains unclear which are the really effective constituents and their mechanisms of action for menopausal syndrome. In this paper, a simple and accurate LC-DAD-MS ${ }^{n}$ method was developed for the comprehensive analysis of the chemical constituents contained in rat plasma and various organs

\footnotetext{
* Correspondence to: Yao Tong, School of Chinese Medicine, the University of Hong Kong, 10 Sassoon Road, Pokfulam, Hong Kong, China. E-mail: tongyao@hkucc.hku.hk

a School of Chinese Medicine, the University of Hong Kong, 10 Sassoon Road, Pokfulam, Hong Kong, China

${ }^{b}$ Institute of Chinese Medical Sciences, the University of Macau, Av. Padre Tomás Pereira S.J., Taipa, Macao, China
}

Abbreviations used: $B B B$, blood-brain barrier; EXD, Erxian Decoction; TCMP, Traditional Chinese medicine prescriptions. 
obtained at certain time points after the oral administration of bioactive EXD fraction. A total of 35 chemical constituents, including the original compounds and some of their metabolites, have been identified or tentatively characterized from the tested samples, and 13 of them were unambiguously identified by a direct comparison with the standards.

\section{Experimental}

\section{Materials and Reagents}

Acetonitrile is of HPLC grade from Merck (Darmstadt, Germany). Doubledistilled water was filtered with $0.22 \mu \mathrm{m}$ nitrocellulose membrane (Mili- $\mathrm{Q}$, Bedford, MA, USA). Chemical standards of berberine chloride, palmatine chloride, jatrorrhizine chloride, menisperine, magnoflorine, ferulic acid, mangiferin, icariin and curculigoside were all purchased from the National Institute for Control of Pharmaceutical and Biological Products (NICPBP, Beijing China). Epimedin A, B, C and baohuoside I were all prepared and elucidated in our laboratory. The purity of each authentic compound was determined to be above $96 \%$ by HPLC analysis. The dried EXD powders were supplied by the NongBen's Company Ltd (Hong Kong, China). The voucher specimens (NB0902) were deposited in the laboratory of the School of Chinese Medicine, The University of Hong Kong.

\section{LC-DAD-MS/MS Conditions}

A Waters Q-Tof micro ${ }^{\mathrm{TM}}$ API mass spectrometer (Waters corp., Milford, USA) was connected to the HPLC instrument (Waters 2487 DAD) via an ESI ion source as interface. Ultra-pure helium $(\mathrm{He})$ was used as the collision gas and high-purity nitrogen $\left(\mathrm{N}_{2}\right)$ was used as the nebulizing gas. The HPLC conditions for LC-DAD-MS analysis were as follows: an XBridge $C_{18}$ column $\left(2.1 \times 150 \mathrm{~mm}, 5.0 \mu \mathrm{m}\right.$, WAT 003110) with an $C_{18}$ Xbridge guard column $(4.0 \times 2.0 \mathrm{~mm}, 5.0 \mu \mathrm{m}$, Waters $)$ was used at $35^{\circ} \mathrm{C}$. A linear gradient elution of solvent A (ultra-pure water contains $0.1 \%$ formic acid, $2 \mathrm{mM}$ ammonium acetate) and solvent $B$ (acetonitrile) was applied with the following program: $0-20 \mathrm{~min}, 10-65 \% \mathrm{~B} ; 20-45 \mathrm{~min}, 65-80 \% \mathrm{~B}$; $45-55 \mathrm{~min}, 80-65 \% \mathrm{~B}$. The re-equilibration time was $10 \mathrm{~min}$ to the next run. The flow rate was $0.25 \mathrm{~mL} / \mathrm{min}$, and the injection volume was $10 \mu \mathrm{L}$. The mass spectrometer conditions were first optimized using flow injection analysis of the standards without HPLC column. The ESI-MS spectra were acquired in both positive and negative modes. The ESI parameters were set as follows: capillary voltage, $3.5 \mathrm{kV}$; sheath gas $\left(\mathrm{N}_{2}\right), 50$ arbitrary units; nebulizer auxiliary gas $\left(\mathrm{N}_{2}\right), 5$ units; extractor, $-6 \mathrm{~V}$ for $(-) \mathrm{ESI}$ and $6 \mathrm{~V}$ for (+) ESI; tube cone voltage, $-45 \mathrm{~V}$ for (-) ESI and $45 \mathrm{~V}$ for (+) ESI. The capillary temperature was $350^{\circ} \mathrm{C}$ and the source block temperature was set at $125^{\circ} \mathrm{C}$, the cone gas flow rate was $50 \mathrm{~L} / \mathrm{h}$, and the mass analyzer scanned from 100 to $1000 \mathrm{u}$. The MS-MS spectra were recorded in auto$\mathrm{MS}^{\mathrm{n}}$ mode, and the fragmentation amplitude was set at $2.0 \mathrm{~V}$.

\section{EXD Sample Preparation}

EXD powders ( $200 \mathrm{~g}$ ) was dissolved in $100 \mathrm{~mL}$ of water, and subject to D101 macroporous resin, flashed with a gradient ethanol-water $(0: 1-90: 10)$ to get several sub-fractions. The $20-80 \%$ ethanol eluents (D101-EXD) were combined and concentrated for final rat administration. The prepared D101-EXD fraction was subjected to HPLC analysis and was proved to contain all of the chemical constituents contained in EXD. At the same time, our pharmacological experiment also showed that the D101-EXD fractions have obvious estrogen-like bioactivities in vitro. Stock solutions of 13 reference compounds were prepared in $75 \%$ methanol at $100 \mu \mathrm{g} / \mathrm{mL}$, respectively, for a direct comparison with the tested EXD sample.

\section{Animals}

Eighteen female Sprague-Dawley rats, weighing 220-250 g, were supplied by the Laboratory Animal Unit, The University of Hong Kong. The rats were divided into three groups (group $A$, drug group for blood withdrawn, $n=6$; group $\mathrm{B}$, drug group for tissues obtained, $n=6$; group $C$, control group for blank plasma and tissues, $n=6$ ) and kept in an airconditioned animal quarters at a temperature of about $24^{\circ} \mathrm{C}$ and a relative humidity of $50-65 \%$, with free access to food and water until $12 \mathrm{~h}$ prior to experiments. The experiment was approved by the Committee on the use of Live Animals in Teaching and Research of Li Ka Shing Faculty of Medicine, the University of HK.

\section{Drug Administration and Sample Preparation}

The D101 fraction (20-80\% ethanol eluent) of EXD extract was dissolved in $0.1 \%$ carboxymethyl cellulose sodium (CMC-Na) aqueous solution and was administrated to the rats $(2.00 \mathrm{~g} / \mathrm{kg}$ body weight) by oral gavage. Blood samples $(100 \mu \mathrm{L})$ were withdrawn from the jugular vein before dosing and subsequently at $0.5,1,2,3,4,8,10$ and $12 \mathrm{~h}$ following administration. The blood samples were placed in heparinized Eppendorf tubes and immediately centrifuged at $10,000 \mathrm{rpm}$ for $5 \mathrm{~min}$ to separate out plasma. The supernatants were mixed and immediately frozen at $-20^{\circ} \mathrm{C}$ until analysis. The plasma collected before drug administration were combined as blank plasma, and the plasma collected from 0.5 to $12 \mathrm{~h}$ were combined as drug containing plasma (2). The rats from group $\mathrm{B}$ were sacrificed by cervical dislocation at $4 \mathrm{~h}$ after drug administration. The blood and organs used as control were all obtained from rats in group C. The original EXD extract was diluted and added to the control plasma (1).

The organs, including kidney and adrenal gland, liver, intestine, ovary and brain were taken out, weighed and washed with ice-cold normal saline. Each organ was put into a clean tube, labeled and stored at $-80^{\circ} \mathrm{C}$ until further processing. The rat organs were homogenized with $0.1 \mathrm{~mol} / \mathrm{L}$ PBS buffer ( $\mathrm{pH} 7.4$ ) in the ratio $1 \mathrm{~g}: 5 \mathrm{~mL}$ and centrifuged at 10,000rpm for $20 \mathrm{~min}$. The supernatant were extracted with ethyl acetate for three times, then combined and concentrated. The residue was dissolved in methanol and centrifuged at $10,000 \mathrm{rpm}$ for $5 \mathrm{~min}$ prior to LC/MS/MS analysis.

\section{Results and Discussion}

The representative LC-DAD-MS chromatograms of blood plasma and organs were shown in Figs 1-5. Based on the direct comparison with chromatograms of those blank samples and EXD original extract (directly added to the rat plasma), a total of 35 compounds were identified from all the tested samples, and their structures are shown in Fig. 6. Among them, 13 compounds were unambiguously identified as berberine, palmatine, jatrorrhizine, menisperine, magnoflorine, ferulic acid, mangiferin, icariin, curculigoside, Epimedin A, B, C and baohuoside I by a direct comparison of the retention time, UV spectra and ESI-MS ${ }^{n}$ fragmentation behavior with the reference compounds. The comparative ESI-MS ${ }^{n}$ spectra of the representative compounds were shown in Fig. 7.

\section{Identification of the Chemical Constituents in Rat Plasma}

There were 21 compounds, including seven alkaloids, 10 phenols and four saponins, detected in the rat plasma (2) collected from 0.5 to $12 \mathrm{~h}$ after the oral administration of active EXD fraction. Compared with the original EXD extract directly added to rat plasma (1), four phenolic acompounds and three alkaloids failed to be detected from the drug-containing rat plasma (2). It showed that most of alkaloids, phenols and saponins contained in EXD could be obviously detected in their original forms from the rat plasma (2) collected during $12 \mathrm{~h}$ after drug administration. Among them, five alkaloids were unambiguously identified as 

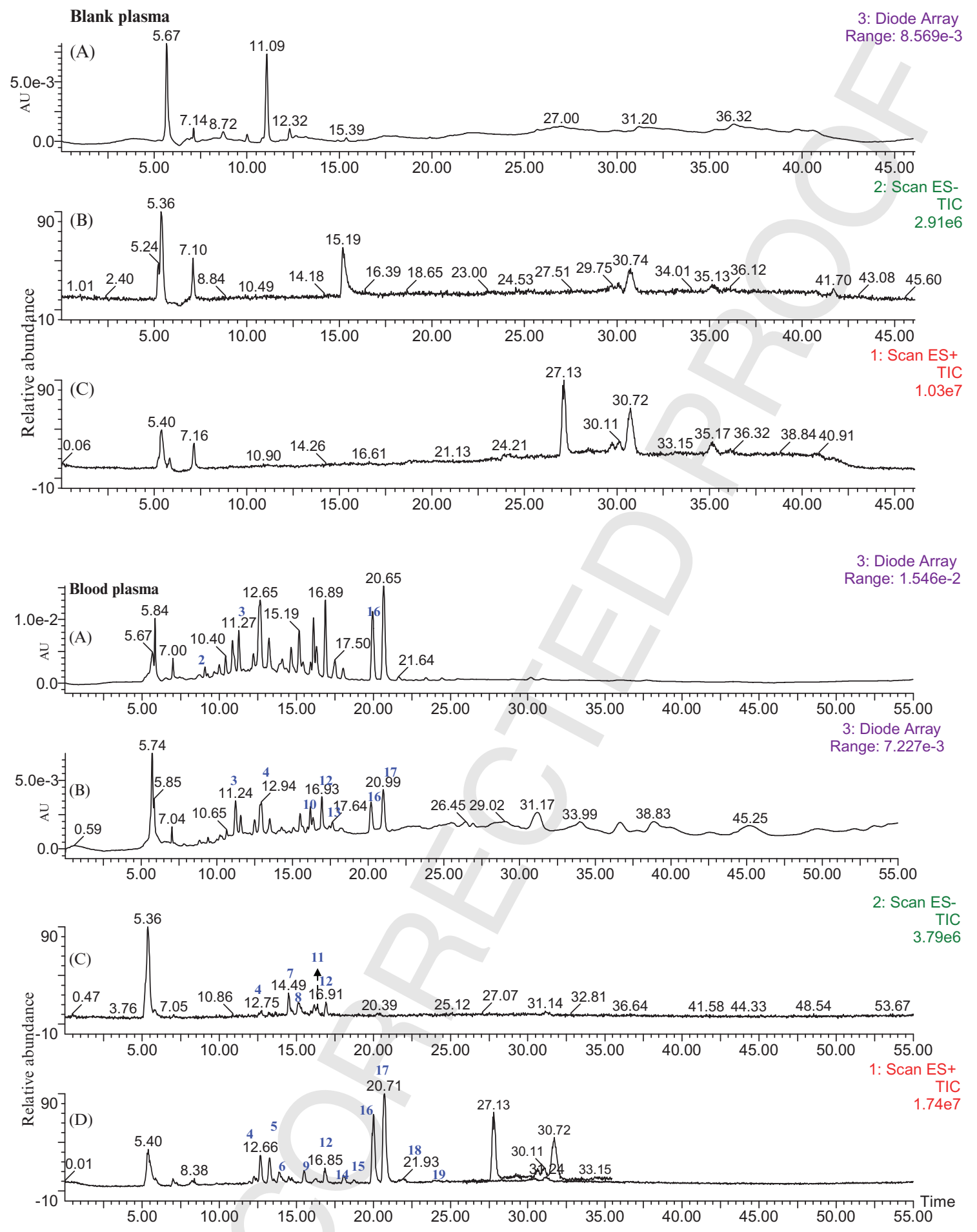

Figure 1. Representative chromatograms of blank plasma. HPLC-DAD chromatogram of blank plasma at $280 \mathrm{~nm}$ (A), the negative ESI-MS mode chromatogram (B) and the positive ESI-MS chromatogram (C) obtained at $4 \mathrm{~h}$ after EXD administration. Representative chromatograms of EXD in rat plasma. HPLC-DAD chromatogram of a blank plasma: (1) sample spiked with original EXD at $280 \mathrm{~nm}(\mathrm{~A})$; rat plasma sample (2) from 0.5 to $12 \mathrm{~h}$ after oral administration of EXD. (B) The HPLC-DAD chromatogram at $280 \mathrm{~nm}$; (C) the negative ESI-MS mode chromatogram; and (D) the positive ESI-MS chromatogram. 

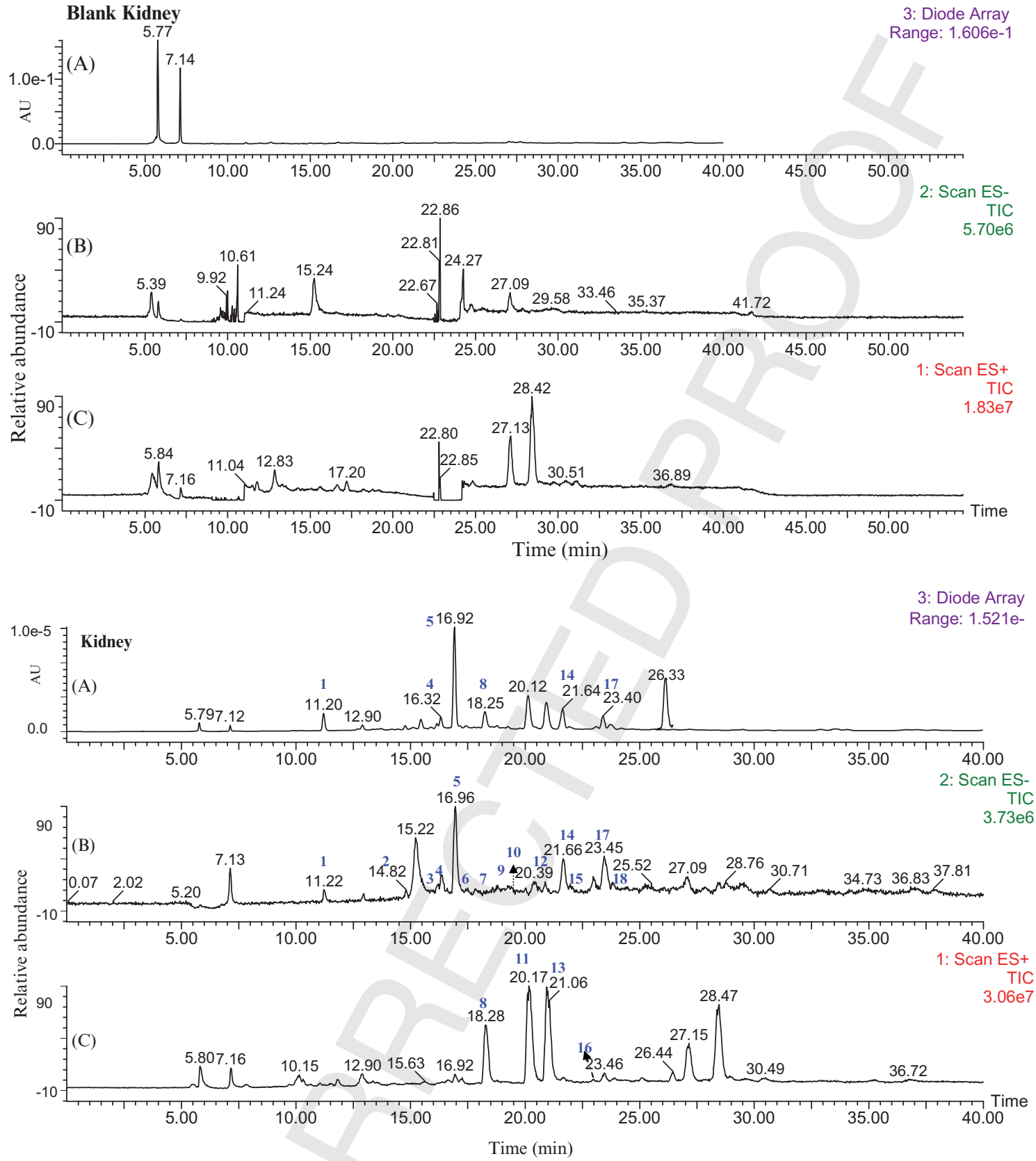

Figure 2. Representative chromatograms of blank rat kidney. HPLC-DAD chromatogram of rat kidney at $280 \mathrm{~nm}$ (A), the negative ESI-MS mode chromatogram (B), and the positive ESI-MS chromatogram (C) obtained at $4 \mathrm{~h}$ after EXD administration. Representative chromatograms of EXD obsorbed in rat kidney. HPLC-DAD chromatogram of rat kidney at $280 \mathrm{~nm}$ (A), the negative ESI-MS mode chromatogram (B), and the positive ESI-MS chromatogram (C) obtained at $4 \mathrm{~h}$ after EXD administration.

magnoflorine, menisperine, jatrorrhizine, palmatine and berberine by a direct comparison with those standard compounds. The molecular structures of the alkaloids were deduced from the positive molecular ion peak at $m / z[M]+$ as well as the corresponding sub-fragments in their $\mathrm{MS}^{\mathrm{n}}$ spectra (Table 1) (Ma et al., 2008; Hua et al., 2007; Lu et al., 2006; Zhang et al., 2006). The ion fragments at $m / z\left[\mathrm{M}-\mathrm{CH}_{3}\right]+,\left[\mathrm{M}-2 \mathrm{CH}_{3}\right]+$ and $\left[\mathrm{M}-\mathrm{CH}_{3} \mathrm{O}-\mathrm{CO}\right]+$, characteristic of the prototype-berberine alkaloids $(\mathbf{2 1}, \mathbf{2 5}, \mathbf{2 6})$, could easily be observed in their ESI-MS spectra, while the ion fragments at $m / z\left[\mathrm{M}-\mathrm{CH}_{3} \mathrm{O}\right]+,\left[\mathrm{M}-\mathrm{C}_{2} \mathrm{H}_{7} \mathrm{~N}\right]+$ and $\left[\mathrm{M}-\mathrm{CH}_{3} \cdot\right.$ $\left.\mathrm{C}_{2} \mathrm{H}_{7} \mathrm{~N}-\mathrm{CH}_{3} \mathrm{O}-\mathrm{CO}-\mathrm{C}_{2} \mathrm{H}_{4}-\mathrm{H}_{2} \mathrm{O}\right]+$ were typical for the aporphine alkaloids $(6,13)$ in the present study. Another nine phenols were all unambiguously identified by a direct comparison with the reference compounds. The anhydroicaritin flavonoids with a prenyl group, which are characteristic for $\mathrm{HE}$ species, also showed some ESI-MS fragmentation properties under the currently applied ESI-MS conditions. In the negative ESI-MS mode, the typical ion peak at $\mathrm{m} / \mathrm{z}$ [M + HCOO-]-could always be observed due to the conjugation of the molecular with the added formic acid in the mobile phase (Zhao et al., 2008). It also indicated that the sugar unite substituted at C-7-O position lost easily, and the ion peaks at $m / z$ [M - 7-O-sugar]- for these flavonoids always 
Figure 3. Representative chromatograms of EXD in rat kidney. HPLC-DAD chromatogram of rat Ovary at $280 \mathrm{~nm}(\mathrm{a})$, the negative ESI-MS mode chromatogram (b), and the positive ESI-MS chromatogram (c) obtained at $4 \mathrm{~h}$ after EXD administration.

Figure 4. Representative chromatograms of EXD in rat Brain. HPLC-DAD

chromatogram of rat brain at $280 \mathrm{~nm}(\mathrm{~A})$, the negative ESI-MS mode chromatogram (B), and the positive ESI-MS chromatogram (C) obtained at $4 \mathrm{~h}$ after EXD administration.

Figure 5. Representative chromatograms of EXD in rat Intestine. HPLC-DAD chromatogram of rat intestine at $280 \mathrm{~nm}(\mathrm{~A})$, the negative ESI-MS mode chromatogram (B) and the positive ESI-MS chromatogram (C) obtained at $4 \mathrm{~h}$ after EXD administration
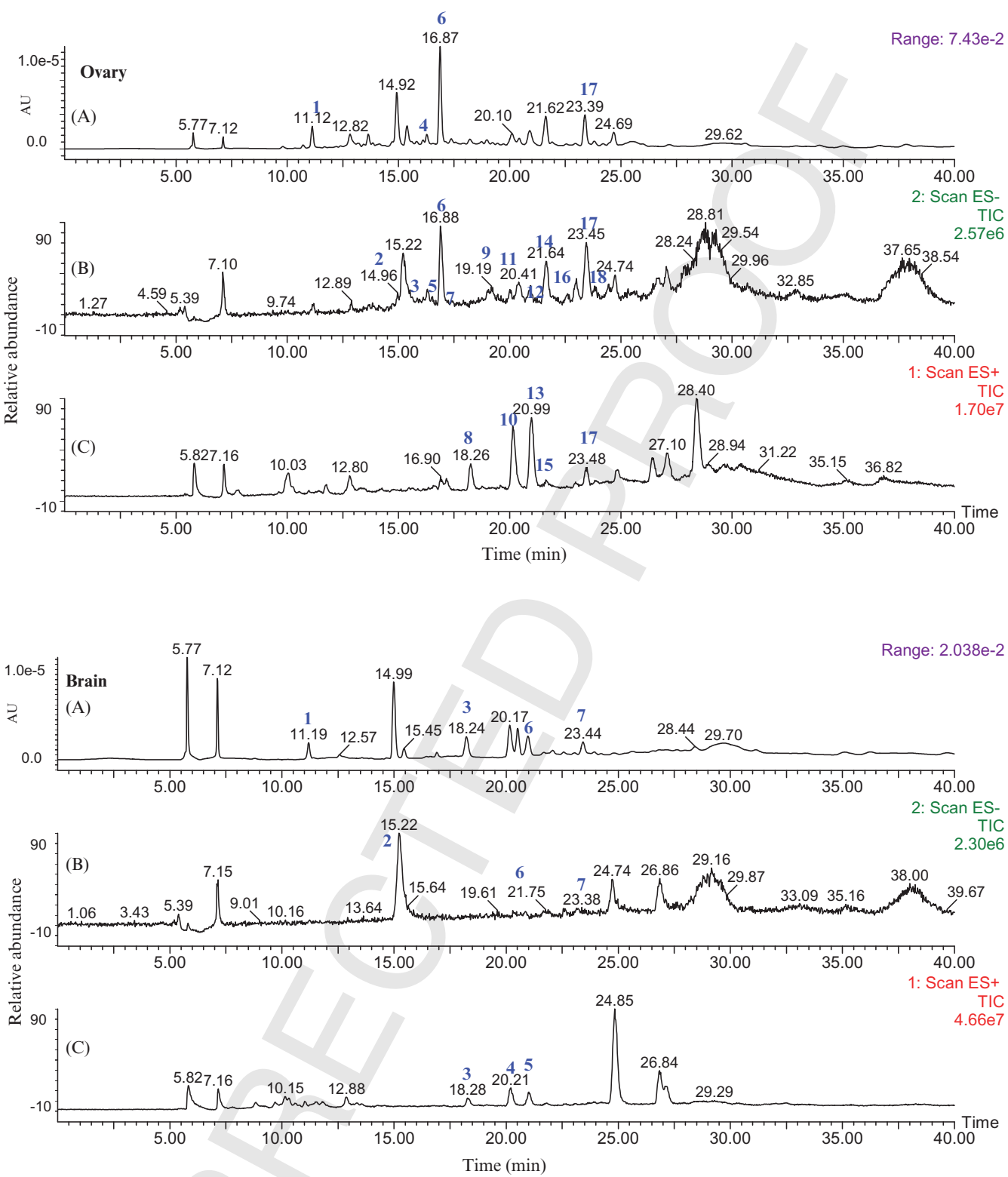

Range: 9.944e-2
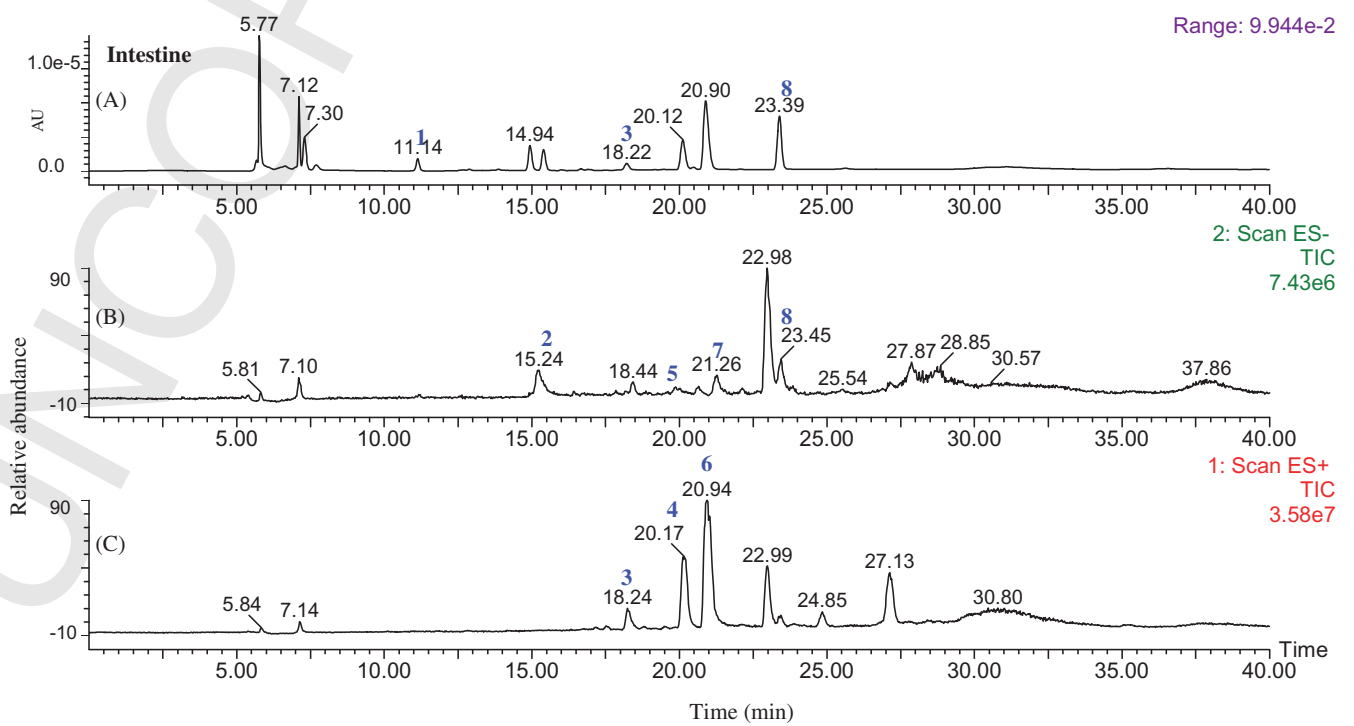


\section{Phenols}<smiles>[R]Oc1cc2c(=O)c3c(O)c([R])c(O)cc3oc2cc1O</smiles>
Glc Glc $\mathbf{1}$

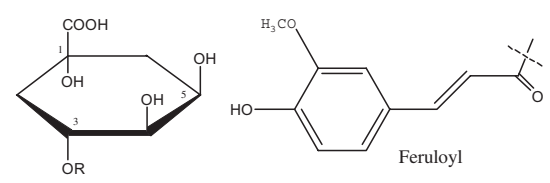

Glc $\quad$ H $\quad 2$<smiles>COc1cc(/C=C/C(=O)O)ccc1OCc1cc(O)ccc1OC(=O)c1c(OC)cccc1OC</smiles>
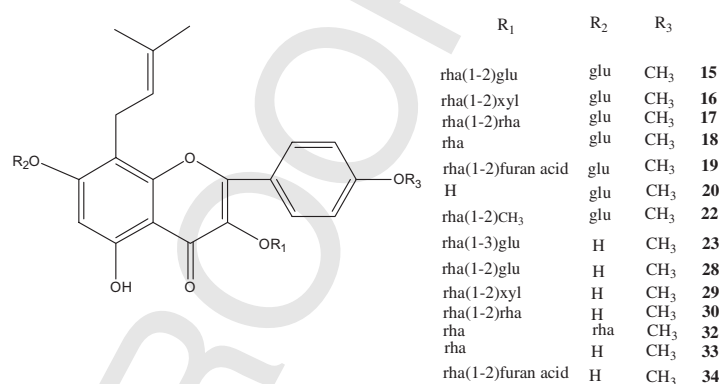

\section{Isoquinoline alkaloid}<smiles>[R]Oc1cc2c(cc1O)[C@@]1(C)Cc3cc(O)c(OC)cc3C[N@@+]1(C)CC2</smiles>

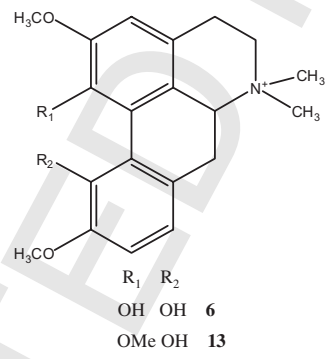

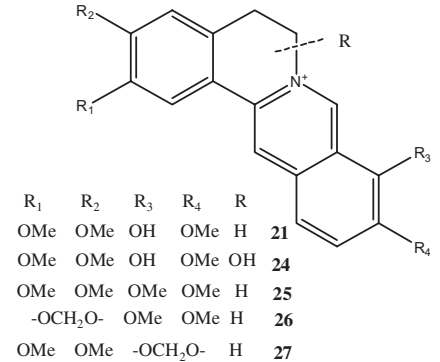

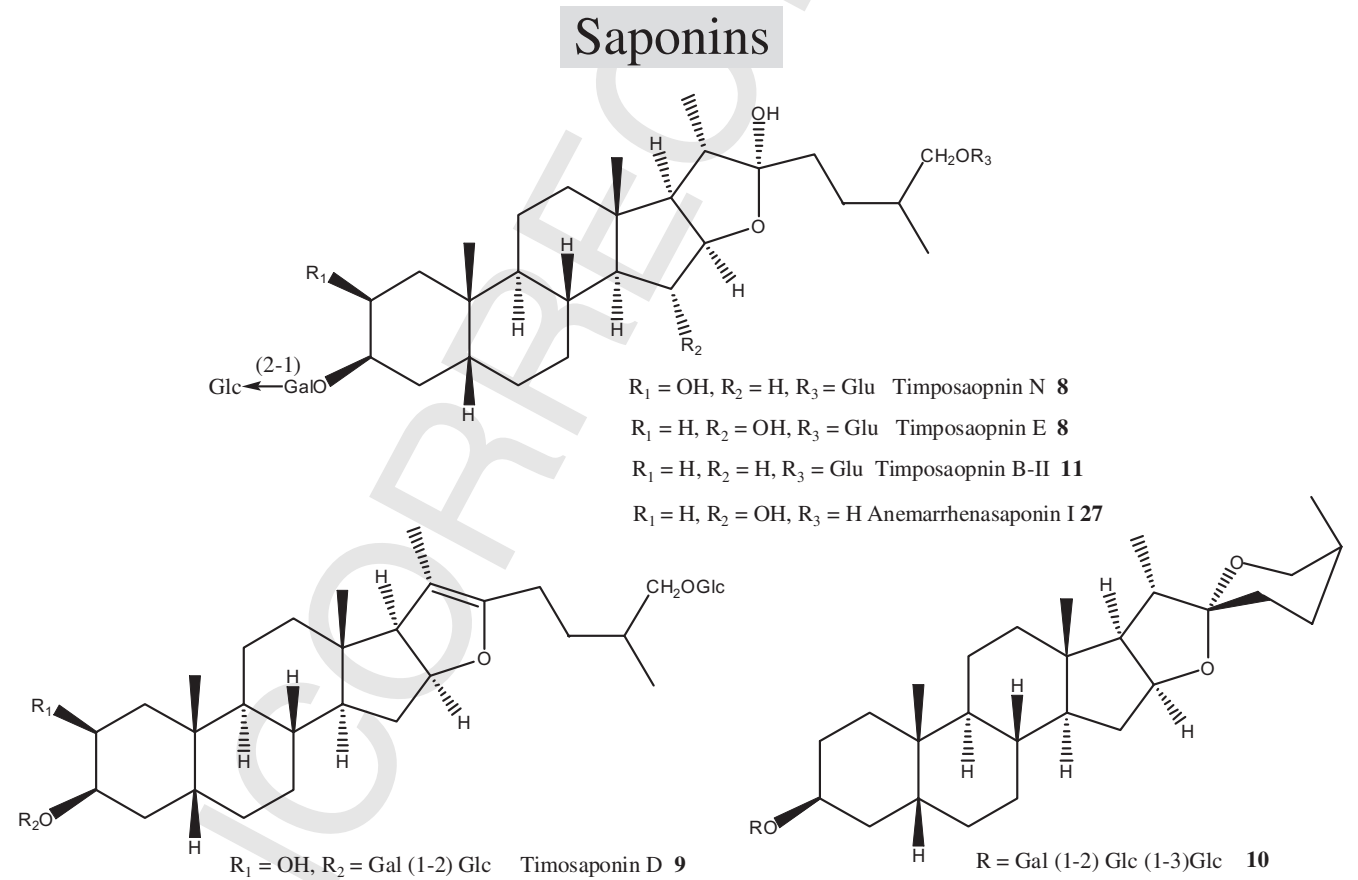

Figure 6. The identified compounds from rat plasma and various organs after oral administration of EXD. 

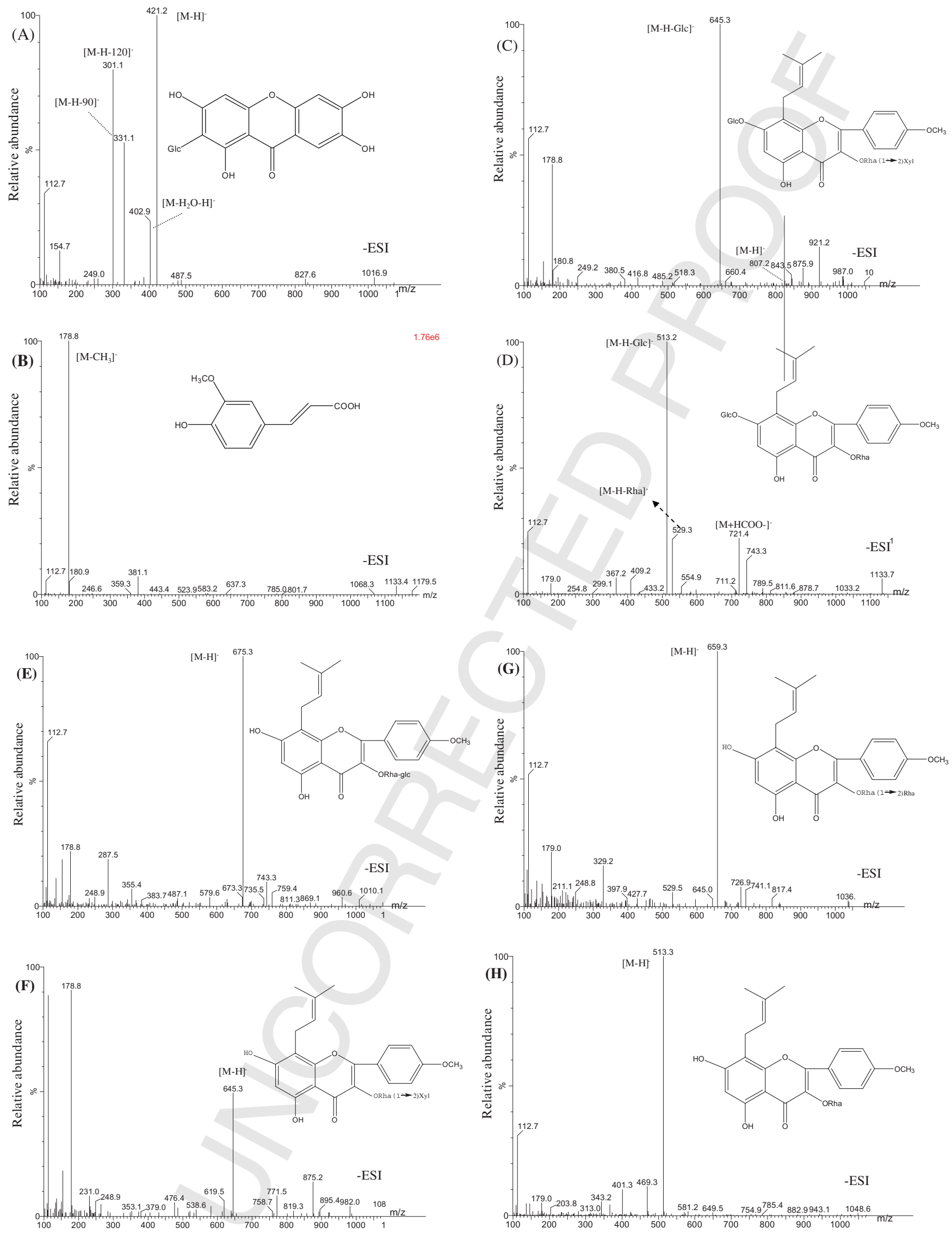

Figure 7. The ESI-MS spectrum of 12 representative compounds. 

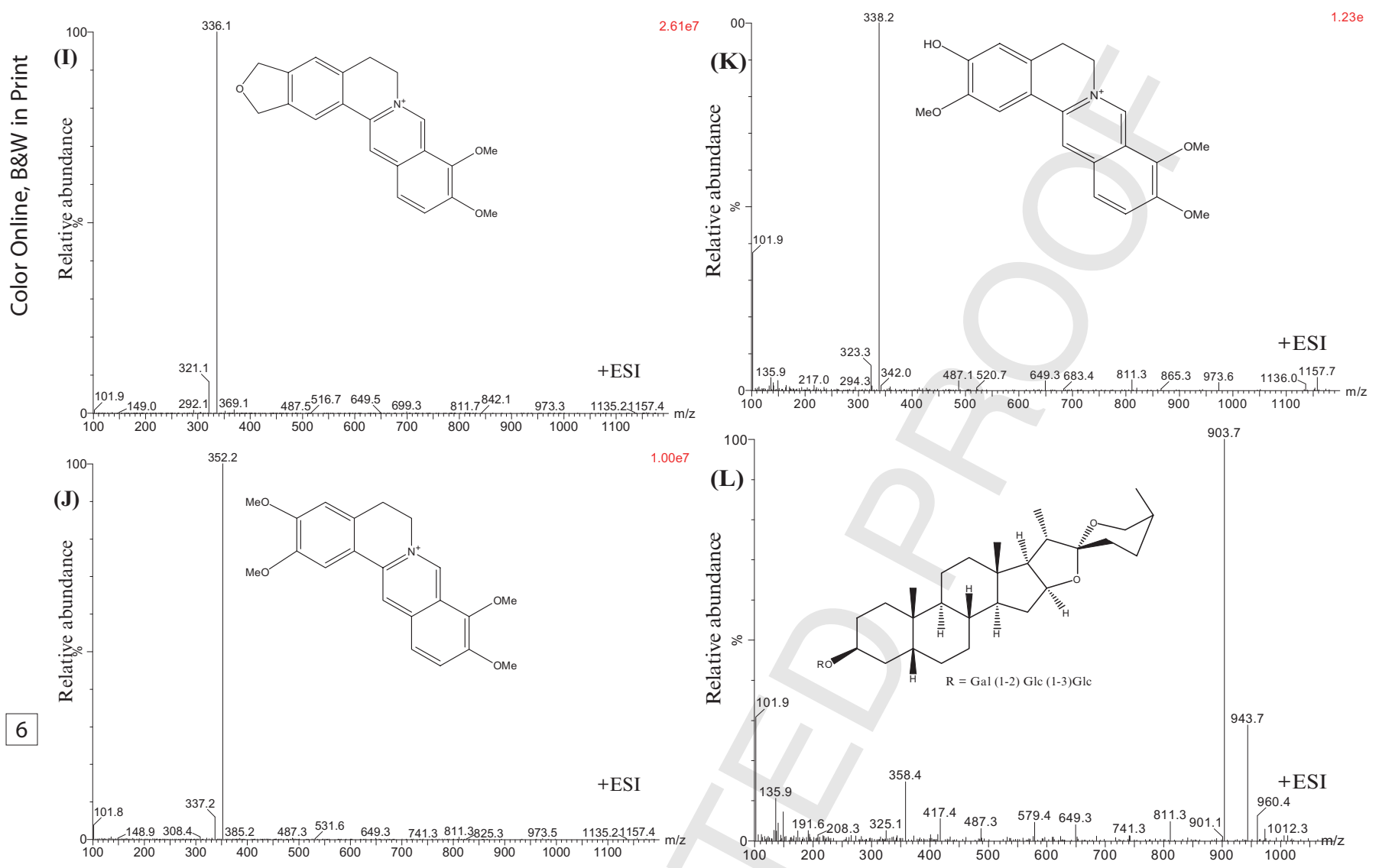

Figure 7. Continued

appeared as the base peaks in their ESI-MS ${ }^{1}$ spectra, while the flavonoid (33) with a 3-O-sugar unit showed its base peak at $\mathrm{m} / \mathrm{z}$ $[\mathrm{M}-\mathrm{H}]-$ in the negative ESI-MS spectrum (Fig. 7). Four saponins mainly contained in Rhizoma Anemarrhenae (RA) were also detected from rat plasma in the negative or positive electrospray mass chromatogram. The quasimolecular ion peak at $m / z$ [M $\mathrm{H}]-$ or $[\mathrm{M}+\mathrm{H}]+$ usually appeared as the base peak in the first moderate ESI-MS spectra, while other fragmentation ions at $\mathrm{m} / \mathrm{z}$ $[\mathrm{M} \pm \mathrm{H}-\mathrm{Glc}]-,[\mathrm{M} \pm \mathrm{H}-\mathrm{Gal}]-,\left[\mathrm{M} \pm \mathrm{H}-\mathrm{H}_{2} \mathrm{O}\right]-$ and $[\mathrm{M} \pm \mathrm{H}-$ sugar units $-\mathrm{H}_{2} \mathrm{O}$ - were always observed and served as the important additional information for the structure elucidation of these saponins (Ma et al., 2008; Hong et al., 1999; Ma et al., 1996; Kang et al., 2006). It was found that the saponins 10 and 11 without any hydroxyl group in their aglycons could be easily detected in the positive ESI-MS chromatogram, while saponins $\mathbf{8}$ and $\mathbf{9}$ that have hydroxyl groups in their molecular aglycons were detected in the negative ESI-MS chromatogram in the present study.

\section{Identification of the Chemical Constituents in Rat Kidney and Adrenal Gland}

A total of 20 compounds, including six alkaloids, 13 phenols (most of them are flavonoids) and one saponin were detected in the rat kidneys and adrenal glands obtained at $4 \mathrm{~h}$ after drug oral administration. It suggested that most of the phenols could be absorbed by rat kidney or adrenal gland both in original or their metabolite forms in about $4 \mathrm{~h}$ after the EXD oral administration, while only several main alkaloids were detected in small amounts in rat kidney and adrenal gland. It is to be noted that four flavo- noids $(\mathbf{2 8 - 3 0}, \mathbf{3 3})$ were detected in rat kidney and adrenal gland in higher amounts than those contained in rat plasma and original EXD extract. Instead, other four flavonoids (15-18), which had higher amounts in the original EXD extract and rat plasma, decreased significantly or disappeared completely in rat kidney and adrenal gland. It is obvious that the flavonoids 28-30 and 33 were transferred from the flavonoids 15-18, respectively, in vivo by losing their glycosyl groups at 3-O position. The results indicated that the flavonoids with more sugar units could easily be degraded or metabolized to their sub-degradation product in vivo. On the other hand, they possibly pointed out that the kidney or its adrenal gland was one of the most sensitive target organs of the phenolic compounds contained in EXD. In addition, they suggested that the original flavonoids and alkaloids metabolize rapidly and could not accumulate in vivo.

Most of the original compounds found in rat kidney and adrenal gland were the same as that found in rat plasma and showed similar fragmentation patterns in their ESI-MS ${ }^{n}$ spectra. The metabolized flavonoids with their $\mathrm{C}-3-\mathrm{O}$-sugar units being hydrolyzed showed the base ion peak mainly at $m / z[M-H]-$ in the ESI-MS spectrum in the present study.

\section{Identification of the Chemical Constituents in Rat Ovary}

Eighteen compounds, including four alkaloids, 13 phenols and one saponin were detected in the rat ovary obtained at $4 \mathrm{~h}$ after the oral administration of EXD. It seemed that only minor amounts of the alkaloids were absorbed by the ovary during this time. Similar to the rat kidney and adrenal gland, the rat ovary 
Table 1. Chemical constituents and their metabolites idendified from rats plasma and organs at certain time points

\begin{tabular}{|c|c|c|c|c|c|c|c|c|c|c|c|c|c|}
\hline \multirow[t]{2}{*}{ No. } & \multirow[t]{2}{*}{$R_{\mathrm{t}}(\min )$} & \multirow[t]{2}{*}{ Identification } & \multicolumn{7}{|c|}{ Detected resource } & \multirow{2}{*}{$\begin{array}{c}\mathrm{M}^{+} \\
(\mathrm{m} / \mathrm{z})\end{array}$} & \multirow{2}{*}{$\begin{array}{c}{[\mathrm{M}-\mathrm{H}]^{-}} \\
(\mathrm{m} / \mathrm{z})\end{array}$} & \multirow{2}{*}{$\begin{array}{c}\text { HPLC-ESI-MS }{ }^{n}(\mathrm{~m} / \mathrm{z}) \text { (\%base peak) } \\
\text { MS }^{2} \text { : Sub-fragments from first base peaks }\end{array}$} & \multirow[t]{2}{*}{$R_{\mathrm{s}}^{\mathrm{a}}$} \\
\hline & & & 1 & 2 & 3 & 4 & 5 & 6 & 7 & & & & \\
\hline 1 & 8.71 & Neomangiferin & + & - & - & - & - & - & - & - & 583 & $M^{2}: 583,421,331,220,293,193$ & 6 \\
\hline 2 & 11.24 & Mangiferin ${ }^{\mathrm{a}}$ & + & + & + & + & - & - & + & - & 421 & $\begin{array}{l}\text { 421, 403, 331, 301(50), 293, 220 } \\
\mathrm{MS}^{2}: 331,301[\mathrm{M}-120]-, 293,193,147\end{array}$ & $\begin{array}{l}6 \\
5\end{array}$ \\
\hline 3 & 11.30 & Lotusine & + & - & - & - & - & - & - & 314 & - & $314,298\left[\mathrm{M}-\mathrm{CH}_{4}\right]+(55), 270,269$ & 5 \\
\hline 4 & 11.85 & (-)-Oblongine & + & - & - & - & - & - & - & 314 & - & $314, \mathbf{2 9 8}, 296,283(5), 268$ & 5 \\
\hline 5 & 12.65 & 3-O-feruoylquinic acid & + & + & - & - & - & - & - & - & 367 & $M S^{2}: 367: 193,191,173,167,112$ & 5 \\
\hline 6 & 13.25 & & + & + & + & - & - & _- & - & 342 & - & $M^{2}: 342: 297,265,209,192,162(15)$ & 5 \\
\hline 7 & 13.48 & Magnoflorine $^{a}$ & + & - & - & - & - & - & - & 342 & - & $M S^{2}: 342: 312,297,264,192,164$ & 6 \\
\hline 8 & 13.71 & Phellodendrine & + & + & - & - & - & - & - & - & 935 & 935, 917, 755, 493;MS²: 773, 742, 611, 455, 449 & 6 \\
\hline 9 & 13.88 & Timosaponin $\mathbf{N}$ & + & + & - & - & - & - & - & - & 917 & $M^{2}: 755, \mathbf{7 7 3}, 611,314$ & 6 \\
\hline 10 & 14.01 & $\begin{array}{l}\text { Timosaponin D } \\
\text { Xilingsaponin B }\end{array}$ & + & + & - & - & - & - & - & $903^{b}$ & - & $\begin{array}{l}903,857,740,434,417,399,356 \\
M^{2}: 740,561,417,399,328,304,286\end{array}$ & $\begin{array}{l}6 \\
4\end{array}$ \\
\hline 11 & 14.49 & Timosaponin B-II & + & + & - & - & - & - & - & $921^{b}$ & 919 & 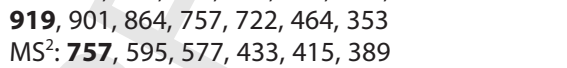 & $\begin{array}{l}5 \\
1\end{array}$ \\
\hline 12 & 15.36 & Ferulic acid ${ }^{a}$ & + & + & + & + & - & - & + & _- & 193 & $193,179,151,149$ & 2 \\
\hline 13 & 15.46 & Menisperine $^{a}$ & + & + & + & - & + & - & - & 356 & - & $M^{2}: 356: \mathbf{3 1 1}, 296,279,225,192,190$ & 2 \\
\hline 14 & 15.63 & Curculigoside $^{a}$ & + & + & - & - & - & - & - & - & 465 & $446,340,303 ; M^{2}: 301,285, \mathbf{2 8 1}, 251$ & 2 \\
\hline 15 & 16.10 & Epimedin $\mathrm{A}^{\mathrm{a}}$ & + & + & - & - & - & _- & - & - & 837 & $837,675,352 ; \mathrm{MS}^{2}: 367,352,311,283$ & 2 \\
\hline 16 & 16.16 & Epimedin $\mathrm{B}^{\mathrm{a}}$ & + & + & - & + & - & - & - & $808^{\mathrm{b}}$ & 807 & $807,645,343 ; \mathrm{MS}^{2}: 367,352,323,311$ & 2 \\
\hline 17 & 16.32 & Epimedin $\mathrm{C}^{\mathrm{a}}$ & + & + & + & + & + & + & - & $823^{b}$ & 821 & $821, \mathbf{6 5 9}, 513 ; \mathrm{MS}^{2}: \mathbf{3 6 7}, 352,323,279$ & \\
\hline 18 & 16.91 & Icariin $^{\mathrm{a}}$ & + & + & + & + & + & + & + & $677^{b}$ & 675 & $\begin{array}{l}721,675, \mathbf{5 1 3}, 409,261 ; \\
M^{2}: 367, \mathbf{3 5 1}, 323,311,280,268\end{array}$ & \\
\hline 19 & 17.47 & $A^{\#}$ & - & - & + & + & - & - & - & - & 819 & $819, \mathbf{6 5 7}, 513,367 ; \mathrm{MS}^{2}: \mathbf{5 1 3}, 366,346,323$ & \\
\hline 20 & 18.01 & Icariside I & - & - & + & + & + & + & - & $531^{\mathrm{b}}$ & 529 & 531, 513, 369; $\mathrm{MS}^{2}: \mathbf{3 6 9}, 313$ & 2 \\
\hline 21 & 18.07 & Jatrorrhizine $\mathrm{a}^{\mathrm{a}}$ & + & + & + & + & + & + & + & 338 & - & 338, 323, 294, 217;MS':323, 294, 148 & 5 \\
\hline 22 & 18.50 & Methoxyl-icariin & - & - & + & - & - & - & - & & 705 & $705,614, \mathbf{5 2 9}, 513$ & 2 \\
\hline 23 & 18.65 & Iso-sagittatoside $\boldsymbol{A}$ & - & - & + & + & - & - & - & - & 675 & $675,578,367,352,311,297$ & 2 \\
\hline 24 & 18.78 & Metablite of alkaloid & - & + & - & - & + & - & - & 370 & - & $370, \mathbf{3 3 8}, 323,279,218,136$ & 5 \\
\hline 25 & 19.98 & Palmatine $^{a}$ & + & + & + & + & + & + & + & 352 & - & $\begin{array}{l}\text { 352, 337, 308, 293; } \\
M^{2}: \text { 337, 322(60), 308, 291, } 190\end{array}$ & $\begin{array}{l}5 \\
5\end{array}$ \\
\hline 26 & 20.82 & Berberine $^{a}$ & + & + & + & + & + & + & + & 336 & - & $\begin{array}{l}\text { 336, 321, 292, 242; } \\
M^{2}: \mathbf{3 2 1}, 292,275,242,186\end{array}$ & $\begin{array}{l}6 \\
6\end{array}$ \\
\hline 27 & 20.86 & Anemarrhenasaponin I & + & + & + & + & + & - & - & - & 757 & $\begin{array}{l}\text { 757, 738, 718, 698, 389, 342, } 197 \\
\mathrm{MS}^{2}: 499,433,415, \mathbf{3 4 2}, 146\end{array}$ & $\begin{array}{l}2 \\
2\end{array}$ \\
\hline 28 & 20.92 & Sagittatoside $\boldsymbol{A}$ & + & - & + & + & + & - & + & $677^{b}$ & 675 & $M^{2}:$ 675, 578, 366, 351(20), 311, 297 & 2 \\
\hline 29 & 21.32 & Sagittatoside $\boldsymbol{B}$ & + & - & - & - & - & - & - & - & 645 & $M^{2}:$ 645, 495, 366, 351(45), 323, 268 & 5 \\
\hline 30 & 21.64 & 2"-O-rhamnosyl-icarisidell & - & - & + & + & + & + & - & $661^{b}$ & 659 & $\begin{array}{l}\text { 659, 513, 367, 366, 352, 351, } 323 \\
\mathrm{MS}^{2}: 659,513, \mathbf{3 6 6}, 351,323,295,280\end{array}$ & $\begin{array}{l}2 \\
2\end{array}$ \\
\hline 31 & 21.67 & Isomer of berberine & + & + & + & + & & - & - & 336 & - & $352, \mathbf{3 3 6}, 321,292,242$ & 2 \\
\hline 32 & 21.89 & Icariin-7-O-rhamnoside & - & - & + & + & - & - & - & - & 659 & $659, \mathbf{5 1 3}, 470,367 ; \mathrm{MS}^{2}: \mathbf{3 6 6}, 351,323$ & 3 \\
\hline 33 & 23.47 & Baohuoside I' (Icariside II) & + & + & + & + & + & + & + & $515^{b}$ & 513 & $\begin{array}{l}\text { 513, 383, 367, 323, 264; } \\
M^{2}: \text { 367, 352,323, 312, } 295\end{array}$ & \\
\hline 34 & 23.89 & $B^{\#}$ & - & - & + & + & - & - & - & & 657 & $679[\mathrm{M}-\mathrm{H}+\mathrm{Na}], 657, \mathbf{5 1 3}, 497,367(45)$ & \\
\hline 35 & 24.74 & Rubiadin-1-methyl ether & + & - & & & 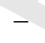 & & + & & 267 & $267,253,251,237,209 ; M^{2}: 209,179(30)$ & \\
\hline $\begin{array}{l}\text { Bol } \\
\text { A }^{\#}: \\
\text { a } T\end{array}$ & $\begin{array}{l}\text { aracte } \\
\text { in-3-r } \\
\text { ompo } \\
\text { mal }\end{array}$ & $\begin{array}{l}\text { ff crude drug item mea } \\
\text { alis; (4) Radix Anemarrhe } \\
\text { he base peaks (100\%) in } \\
\text {-4)furan acid; } B^{\#} \text { : Baohu } \\
\text { s were identified unamb }\end{array}$ & I-Ms & $\begin{array}{l}\text { S spe } \\
\text { rha(1 } \\
\text { ly by }\end{array}$ & & & & & & die & ong & $\begin{array}{l}\text { abolites of the original compounds; } \\
\text { hes; }{ }^{b}[\mathrm{M}+\mathrm{H}]^{+} \text {. }\end{array}$ & \\
\hline
\end{tabular}

also proved to be the one of the most sensitive target organs of the anti-oxidant flavonoids contained in EXD. It showed that most of the detected flavonoids were the sub-degradation products of the original ones with the C-7-O-glycosyl being hydrolyzed. This phenomenon suggested that most of the flavonoid could pass through the placenta barrier easier than alkaloids. The 18 compounds showed a similar ESI-MS ${ }^{n}$ fragmentation behavior to those detected in rat kidney and adrenal glands.

\section{Identification of the Chemical Constituents in Rat Small Intestine}

A total of 12 compounds, including five alkaloids, six flavonoids and one saponin were detected in the rat intestine obtained at
$4 \mathrm{~h}$ after the oral administration of EXD. It could be seen that fewer compounds originally contained in EXD were detected from the rat intestine at $4 \mathrm{~h}$ after drug administration. This indicated that most of the chemical constituents contained in EXD possibly have been eliminated from rat intestine during this time. The ESI-MS ${ }^{n}$ fragmentation patterns of these compounds were identical to those detected in rat plasma and kidneys.

\section{Identification of the Chemical Constituents in Rat Liver}

Only nine compounds, including three alkaloids, six flavonoids were detected in the rat liver obtained in $4 \mathrm{~h}$ after the oral administration of EXD. Most of the flavonoids were found to be the submetabolites with some glucosyl units at $\mathrm{C}-3-\mathrm{O}$ being hydrolyzed 
through the metabolism. The liver is one of the heaviest organs in rat, while in the present study most of the original compounds failed to be detected in liver. This possibly could be explained by the rapid metabolism or elimination velocity of these chemicals in rat liver. The fragmentation patterns of these compounds were similar to those detected in rat plasma and kidneys.

\section{Identification of the Chemical Constituents in Rat Brain}

Nine typical compounds, including the maniferin, ferulic acid, icarrin, baohuoside $\mathbf{I}$, sagittatoside $\mathbf{A}$, rubiadin-1-methyl ether, berberine, palmatine and jatrorrhizine were all obviously detected in rat brains obtained at $4 \mathrm{~h}$ after the oral administration of EXD. It is well known that any drugs or chemical constituents which can enter the brain must overcome the blood-brain barrier (BBB) first, and only those compounds that have a smaller molecular size and lower polarity can pass through the BBB and be absorbed into the brain easily. It is suggested that some of the original compounds contained in EXD can get through the BBB and act on the brain directly. The baohuoside $I$, in relatively higher amounts, should be the final metabolite of the original flavonol glycosides $(\mathbf{1 5 - 1 9 ; 2 8 - 3 0 )}$ by losing some of their sugar units in their molecular during the metabolism process. The ESI-MS $^{n}$ spectra of these compounds were comparable to those observed in rat plasma and rat ovary.

\section{Discussion and Conclusion}

Through the combined LC-DAD-MS ${ }^{n}$ techniques, a total of 35 compounds were simultaneously detected and identified from rat plasma and various organs in their original or metabolitic forms after oral administration of the bio-active EXD fraction. The results indicated that most of the phenols (mainly flavonoids), alkaloids and saponins could easily be absorbed into rat blood through oral administration of EXD. The flavone glycosides could be metabolized or eliminated from the body quickly; however their sub-degradation product will stay in kidney, adrenal gland and ovary for a longer time (at least $4 \mathrm{~h}$ ). It is also suggested that the kidney, adrenal gland and ovary are the most sensitive target organs for those antioxidative flavonoids and their sub-metabolites. More interestingly, several small molecular compounds could pass through the BBB and be absorbed into rat brain directly. On the other hand, the isoquinoline alkaloids as the main constituents of Cortex Phellodendri were easily detected from all of the tested rat organs and plasma, and some of their metabolites were also found in rat liver and kidney after drug administration. Bioactive studies by our research group also found that these detected flavonoids, alkaloids and saponins are the most effective constituents contained in EXD. Some metabolized flavonoids, e.g. the baohuoside I, were also proved to have obvious estrogenlike bioactivities in vitro. A further pharmacological investigation of the sub-metabolites based on our pharmacokinetic study will be carried out in the future.

It is well known that there are two major routes of drug administration-enteral and parenteral (Fig. 8). Giving a drug orally is the most common route of enteral administration, especially for the TCM formula when used in the clinic. Only the constituents successfully absorbed into the blood and kept at a considerable concentration level in target organs can perform their therapeutic functions. Our present work through the comprehensive analysis of all the chemical constituents and their metabolites contained in rat plasma and various organs at certain time points, provides the preliminary profile of the absorption, distribution, metabolism and elimination of EXD in vivo (Fig. 9). A more comprehensive pharmacokinetic study about the various rat organs and plasma obtained at different time points should be followed up in future. The results will on the other hand elucidate the real action target and medicinal mechanism of EXD in vivo.

\section{Acknowledgements}

This research was supported in part by a grant from Small Project Funding (RCGAS0768162812; 200607176131), Seed Funding Programme for Applied Research (no. 200802160025), the University of Hong Kong and Liu Hao Tsing Foundation Ltd. The authors would also like to thank the Physical \& Chemical Testing Center at the Jinan University, Guangzhou, for their assistance in NMR and ESIMS experiments and the Nongben' Company in Hong Kong for supplying the EXD samples.

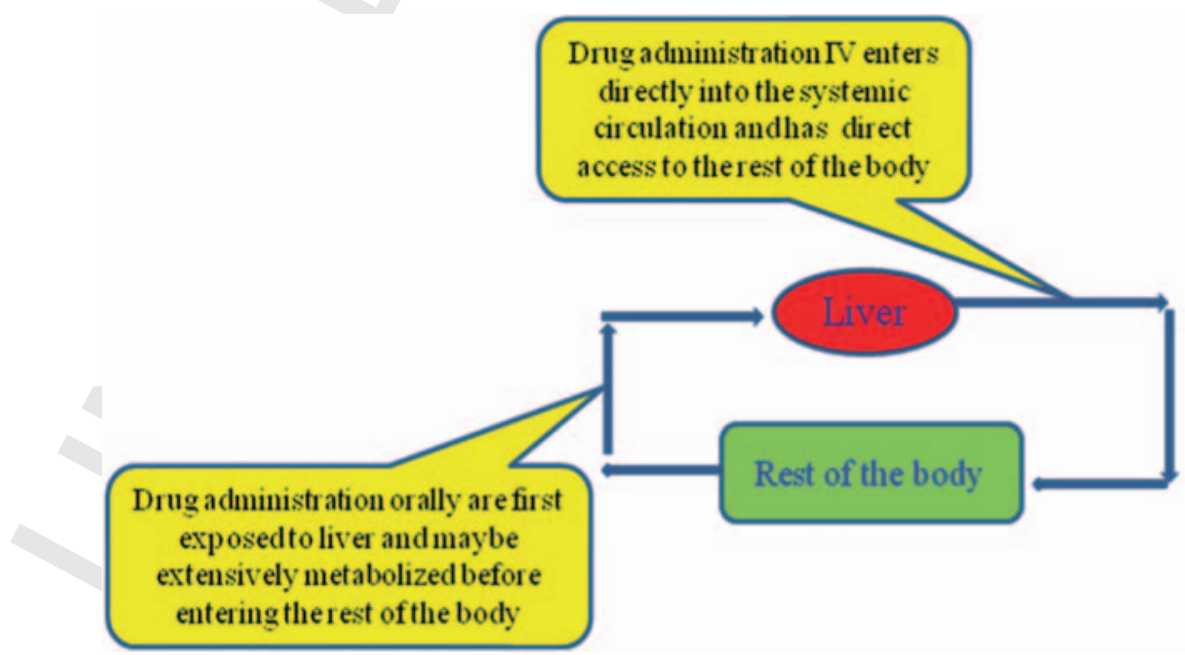

Figure 8. First-pass metabolism can occur with orally administrated drugs. 

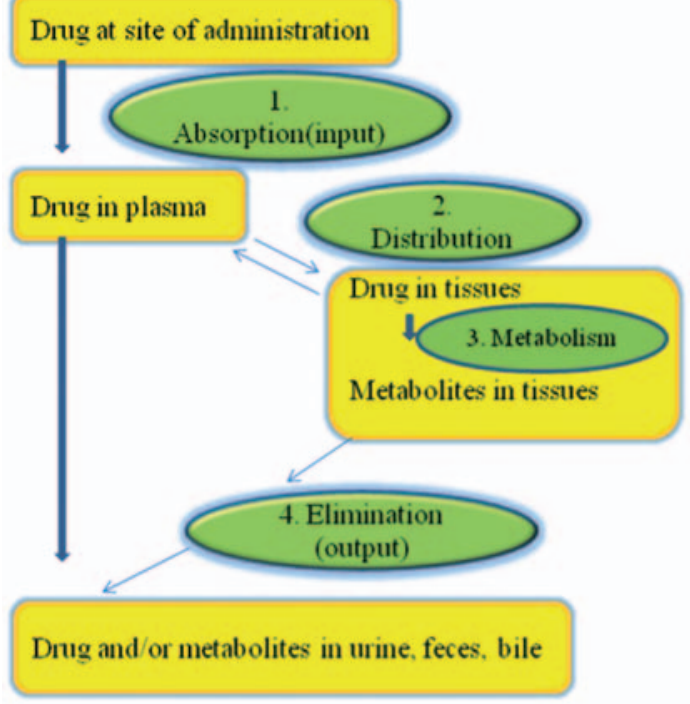

Figure 9. Schematic representation of drug absorption, distribution, metabolism and elimination.

\section{References}

Chen XJ, Guo BL, Li SP, Zhang QW, Tu PF and Wang YT. Simultaneous determination of 15 flavonoids in Epimedium using pressurized liquid extraction and high-performance liquid chromatography. Journal of Chromatography A 2007; 1163: 96-104.

Chen XJ, Ji H, Zhang QW, Tu PF, Wang YT, Guo BL and Li SP. A rapid method for simultaneous determination of 15 flavonoids in Epimedium using pressurized liquid extraction and ultra-performance liquid chromatography. Journal of Pharmaceutical and Biomedical Analysis 2008; 46(2): 226-135.

Hong YF, Zhang GM, Sun LN, Han GY and Ji GZ. Isolation and identification of steroidal saponins from Anemarrhena asphodeloides Bunge. Acta Pharmaceutica Sinica 1999; 34(7): 518-521.

Hua WY, Ding L, Chen Y, Dong B, He JC and Xu GL. Determination of berberine in human plasma by liquid chromatography-electrospray ionization-mass spectrometry. Journal of Pharmaceutical and Biomedical Analysis 2007; 44(4): 931-937.
Kang LP, Ma BP, Shi TJ, Zhang J and Xiong CQ. Two new furostanol saponins from the rhizomes of Anemarrhena asphodeloides. Acta Pharmaceutica Sinica 2006; 41(6): 527-532.

Kite GC, Porter EA and Simmonds MS-J. Chromatographic behaviour of steroidal saponins studied by high-performance liquid chromatography-mass spectrometry. Journal of Chromatography A 2007; 1148: 177-183.

Li YF, Gong ZH, Yang M, Zhao YM and Luo ZP. Inhibition of the oligosaccharides extracted from Morinda officinalis, a Chinese traditional herbal medicine, on the corticosterone induced apoptosis in PC12 cells. Life Science 2003; 72: 933-942.

Liu Q, Shi JR, Yang Y, Fang ZQ, Liang SH and Guo RX. Effects on secretory function of rat gonad by erxian decoction and its disassemblied pprescriptions. China Journal of Chinese Materia Medica 2005; 30(13): 1023-1026.

Lu T, Liang Y, Song J, Xie L, Wang GJ and Liu XD. Simultaneous determination of berberine and palmatine in rat plasma by HPLC-ESI-MS after oral administration of traditional Chinese medicinal preparation Huang-Lian-Jie-Du decoction and the pharmacokinetic application of the method. Journal of Pharmaceutical and Biomedical Analysis 2006; 40(5): 1218-1224.

Ma BP, Dong JX, Wang BJ and Yan XZ. Studies on the furostanol saponins from Anemarrhena asphodeloides Bunge. Acta Pharmaceutica Sinica 1996; 31(4): 271-277.

Ma CH, Fan MS, Tang YH, Li ZX, Sun ZL, Ye G and Huang CG. Identification of major alkoloids and steroidal saponins in rat serum by HPLC-diode array detection-MS/MS following oral administration of HuangbaiZhimu herb-pair extract. Biomedical Chromatography 2008; 22: 835-850.

Nian H, Qin LP, Zhang QY, Zheng HC, Yu Y and Huang BK. Antiosteoporotic activity of Er-Xian Decoction, a traditional Chinese herbal formula, in ovariectomized rats. Journal of Ethnopharmacology 2006; 108(1): 96-102.

Sze SCW, Tong Y, Zhang YB, Zhang ZJ, Lan ASL, Wang HK, Tsang KW and $\mathrm{Ng}$ TB. A novel mechanism: Erxian Decoction. A Chinese medicine formula, for relieving menopausal syndrome. Journal of Ethnopharmacology 2009; 123: 27-33.

Zhang YF, Shi QR, Shi PY, Zhang WD and Cheng YY. Characterization of isoquinoline alkaloids, diterpenoids and steroids in the Chinese herb Jin-Guo-Lan (Tinospora sagittata and Tinospora capillipes) by highperformance liquid chromatography/electrospray onization with multistage mass spectrometry. Rapid Communications in Mass Spectrometry 2006; 20(15): 2328-2342.

Zhao HY, Sun JH, Fan MX, Li F, Zhou L, Li Z, Han J, Wang BR and Guo DA. Analysis of phenolic compounds in Epimedium plants using liquid chromatography coupled with electrospray ionization mass spectrometry Journal of Chromatography A 2008; 1190(1-2): 157-181. 
Dear Author:

During the preparation of your manuscript for publication, the questions listed below have arisen. Please attend to these matters and return this form with your proof.

Many thanks for your assistance.

\begin{tabular}{|l|l|l|}
\hline $\begin{array}{l}\text { Query } \\
\text { References }\end{array}$ & Query & Remarks \\
\hline 1. & $\begin{array}{l}\text { AUTHOR: Ge et al., 2007 and Wang et al., 2005 not in } \\
\text { Reference list? }\end{array}$ & \\
\hline 2. & AUTHOR: Gong et al., 2003 not in Reference list? & \\
\hline 3. & AUTHOR: define HE? & \\
\hline 4. & AUTHOR: Chen, please correct page numbers & \\
\hline 5. & AUTHOR: Li et al., 2003 not mentioned in text? & \\
\hline 6. & AUTHOR: please provide copy of Figs 1-7 with larger lettering & \\
\hline
\end{tabular}

